\section{Procalcitonin in Takayasu Arteritis}

To the Editor:

Procalcitonin (PCT) is an acute-phase protein, a precursor of the hormone calcitonin ${ }^{1}$. Microbial constituents and proinflammatory mediators such as tumor necrosis factor- $\alpha$ (TNF), interleukin 6 (IL-6), and interferon- $\gamma$ induce ubiquitous PCT expression during bacterial, parasitic, or fungal infections ${ }^{1,2}$. PCT enhances inflammatory response during sepsis, when excessive PCT production can be toxic, increasing mortality in animal models $^{1}$. In humans, PCT has been demonstrated to be a more accurate marker of systemic bacterial infections than C-reactive protein $(\mathrm{CRP})^{3}$, and it correlates with the severity of sepsis and mortality risk ${ }^{1}$. For these reasons, PCT is increasingly used for diagnosis, prognostic stratification, and treatment of patients with systemic bacterial or fungal infections. However, PCT elevation has been reported in noninfectious conditions, including inflammatory states associated with antineutrophil cytoplasmic antibodies-associated vasculitis, Kawasaki disease, and Goodpasture syndrome ${ }^{2}$. The clinical usefulness of PCT as a biomarker in patients with systemic autoimmune diseases has not been fully defined ${ }^{2}$. One metaanalysis showed that PCT had higher specificity but lower sensitivity than CRP in discriminating sepsis from disease flares ${ }^{4}$.

Takayasu arteritis (TA) is a rare, idiopathic inflammatory arteritis. TNF and IL-6, the cytokines responsible for systemic inflammatory reactions, have been proposed to be involved in TA pathogenesis and to represent possible therapeutic targets for $\mathrm{TA}^{5}$. Concordantly, systemic response with acute reactant elevation often but not always accompanies active disease ${ }^{5}$. To our knowledge, no data are available to assess the performance of PCT in TA. We thus wondered whether active TA was associated with PCT elevation in the absence of demonstrable systemic infection, possibly jeopardizing the differentiation between disease flares and bacterial sepsis.

Between March and June 2013, we evaluated levels of PCT, CRP, and erythrocyte sedimentation rate (ESR) in 41 consecutive patients with TA regularly followed at our center who had no concurrent systemic infections, as assessed by a thorough clinical assessment and parallel evaluation of leukocyte counts. Patient conditions were routinely verified again after 2 months, and in no case did infectious events become manifest in the 8 weeks after venipuncture. All patients with TA satisfied the American College of Rheumatology criteria for TA classification in the absence of a demonstrable infection. Activity status of TA was evaluated according to US National Institutes of Health criteria. In parallel, PCT and CRP were evaluated in a control group of 49 patients with severe sepsis and septic shock within $24 \mathrm{~h}$ from emergency room admission. All patients gave written consent to the study. PCT serum levels were assessed with electrochemiluminiscent immunoassay (ECLIA, Roche Diagnostics $\mathrm{GmbH}$ ). Statistical elaborations were performed with SPSS statistic 15.0. Inferential statistic was performed with nonparametric tests.

Table 1 describes the principal characteristics of the 2 groups. The age at disease onset and sex distribution of the TA group was similar to other reports in the Italian population ${ }^{6}$. Mean prednisone dose was $6.4 \mathrm{mg} /$ day (SD $8.1 \mathrm{mg} /$ day). Twenty-nine patients took immunosuppressive agents, 16 received TNF inhibitors, and 2 tocilizumab. None of the patients with TA had increased PCT levels, although 14/41 patients (34\%) had active TA and 14 and 13 patients, respectively, had increased ESR and CRP. Mean PCT value was $0.02 \mu \mathrm{g} / 1(\mathrm{SD} 0.01 \mu \mathrm{g} / \mathrm{l})$ and the maximum value was $0.08 \mu \mathrm{g} / 1$ (observed in a newly diagnosed untreated patient). TA activity influenced ESR and CRP but not PCT values, while concurrent immunosuppressive therapies did not influence any of the 3 biomarkers (Table 2). As expected, PCT levels were increased in the group of patients with severe sepsis and septic shock, where mean PCT was $28.8 \mu \mathrm{g} / \mathrm{l}$ (SD $53.3 \mu \mathrm{g} / \mathrm{l}$ ). Our data thus indicate that PCT is not elevated in real-life clinical practice with patients with TA, not even during disease flares, suggesting that PCT could be used as a marker of sepsis in these subjects.

Our study has limitations. First, it is a real-life cross-sectional analysis in which all patients with TA had already been diagnosed and followed. Thus, few patients had the very high inflammatory state that is sometimes
Table 1. Characteristics of the patients with TA $(n=41)$ and those with severe sepsis or septic shock.

Patients with TA

\begin{tabular}{|c|c|}
\hline Male/female & $3 / 38$ \\
\hline Age, $\mathrm{yrs}^{1}$ & $45(12)$ \\
\hline Age at disease onset, $\mathrm{yrs}^{1}$ & $33(12)$ \\
\hline No. receiving immunosuppressive agents & 29 \\
\hline No. receiving TNF inhibitors & 16 \\
\hline No. receiving tocilizumab & 2 \\
\hline Prednisone dose (mg/day) ${ }^{1}$ & $6.4(8.1)$ \\
\hline No. with active disease ${ }^{3}$ & 14 \\
\hline $\mathrm{ESR}, \mathrm{mm} / \mathrm{h}^{2}$ & $22(21 ; 1-78)$ \\
\hline $\mathrm{CRP}, \mathrm{mg} / \mathrm{l}^{2}$ & $6.36(9.25 ; 0.03-39.6)$ \\
\hline Blood leukocytes, cells $/ \mu 1^{2}$ & $7800(2400 ; 4000-1400)$ \\
\hline Blood neutrophils, cells $/ \mu 1^{2}$ & $4500(1800 ; 1900-9000)$ \\
\hline No. with ESR elevations ${ }^{4}$ & 14 \\
\hline No. with CRP elevations ${ }^{4}$ & 13 \\
\hline $\mathrm{PCT}, \mu \mathrm{g} / 1^{2}$ & $0.02(0.01 ; 0.02-0.08)$ \\
\hline \multicolumn{2}{|c|}{ Patients with severe sepsis and septic shock, $n=49$} \\
\hline Male/female & $26 / 23$ \\
\hline Age, yrs ${ }^{1}$ & $74(10)$ \\
\hline No. patients with severe sepsis & 33 \\
\hline No. patients with septic shock & 16 \\
\hline $\mathrm{CRP}, \mathrm{mg} / \mathrm{l}^{2}$ & $198(149 ; 0.50-303)$ \\
\hline PCT, $\mu \mathrm{g} / \mathrm{l}^{2}$ & $28.8(53.3 ; 0.05-243)$ \\
\hline Blood leukocytes, cells $/ \mu 1^{2}$ & $17,000(17,000 ; 1100-88,000)$ \\
\hline
\end{tabular}

${ }^{1}$ Mean values (SD). ${ }^{2}$ Mean values (SD; range). ${ }^{3}$ According to NIH criteria. ${ }^{4}$ According to local laboratory upper limit of normal. NIH: US National Institutes of Health; TA: Takayasu arteritis; TNF: tumor necrosis factor; ESR: erythrocyte sedimentation rate; CRP: C-reactive protein; PCT: procalcitonin.

present at disease onset before treatment. Second, because we do not have a control group of patients with septic TA, we cannot assess the sensitivity of PCT in this situation. A metaanalysis showed a relatively low sensitivity of PCT for diagnosing systemic infection in patients with autoimmune disease $^{4}$, and it cannot be excluded that the immunodeficiency status associated with systemic autoimmune diseases and their treatments could limit PCT diagnostic accuracy. Patients with refractory TA are increasingly treated with biologic agents such as TNF or IL-6 inhibitors, and TNF has been proposed to induce in vivo the PCT synthesis $^{1}$, although some findings do not confirm this hypothesis ${ }^{7}$. Given the importance of the diagnosis of systemic infections in immunocompromised patients, the assessment of PCT sensitivity in patients undergoing immunosuppressive regimens, especially those including agents blocking TNF and IL-6, needs further research.

Our results indicate that PCT is not elevated in patients with TA, and suggest that PCT elevations should raise the question of sepsis in these subjects.

ENRICO TOMBETTI, MD; MARIA CHIARA DI CHIO, MD; SILVIA SARTORELLI, MD; ANDREA SEGALINI, MD; YOLE VELLA, MD; MATTEO SPALLUTO, MD; MARIA GRAZIA SABBADINI, MD, Professor, Internal Medicine and Rheumatology; ELENA BALDISSERA, MD; ANGELO MANFREDI, MD, Assistant Professor of Rheumatology and Clinical Immunology, Unit of Internal Medicine and Immunology, San Raffaele Scientific Institute, Milan, Italy. Address correspondence to Dr. E. Tombetti, San Raffaele University Hospital, Unit of Internal Medicine and Clinical Immunology, Via Olgettina 60, 20132 Milan, Italy. E-mail: tombetti.enrico@hsr.it

Supported by the Ministero della Salute (Ricerca Finalizzata 2009 to Dr. Manfredi) and the Ministero dell'Istruzione, dell'Universitá e della Ricerca. 
Table 2. ESR, CRP, and PCT values in patients with TA according to activity status and concurrent immunological therapies.

\begin{tabular}{lcccc}
\hline & $\begin{array}{c}\text { Active Without } \\
\text { Therapies }\end{array}$ & $\begin{array}{c}\text { Inactive Without } \\
\text { Therapies }\end{array}$ & $\begin{array}{c}\text { Active While Receiving } \\
\text { Therapies }\end{array}$ & $\begin{array}{c}\text { Inactive While Receiving } \\
\text { Therapies }\end{array}$ \\
\hline No. patients & 1 & 3 & 13 & 24 \\
Mean ESR, $\mathrm{mm} / \mathrm{h}^{1}$ & 68 & $14(8 ; 7-23)$ & $35(23 ; 3-78)$ & $11(9 ; 1-34)$ \\
Mean CRP, $\mathrm{mg} / \mathrm{l}^{2}$ & 24 & $2.0(1.0 ; 0.9-2.7)$ & $12(13 ; 0.9-40)$ & $3.0(4.4 ; 0.1-19)$ \\
Mean PCT, $\mu \mathrm{g} / \mathrm{l}^{3}$ & 0.08 & $0.02(0.1 ; 0.02-0.2)$ & $0.02(0.01 ; 0.02-0.04)$ & $0.02(0.01 ; 0.02-0.06)$ \\
\hline
\end{tabular}

${ }^{1}$ ESR values (active vs inactive patients) $\mathrm{p}=0.001$; ESR values (TA patients without therapy vs receiving therapy) $\mathrm{p}=0.419 .{ }^{2} \mathrm{CRP}$ values (active vs inactive TA patients) $\mathrm{p}=0.003$; CRP values (TA patients without therapy vs receiving therapy) $\mathrm{p}=0.757 .{ }^{3}$ PCT values (active vs inactive TA patients) $\mathrm{p}=0.600$; PCT values (TA patients without therapy vs receiving therapy) $\mathrm{p}=0.689$. TA: Takayasu arteritis; ESR: erythrocyte sedimentation rate; CRP: C-reactive protein; PCT: procalcitonin.

\section{REFERENCES}

1. Becker KL, Nylen ES, White JC, Muller B, Snider RH Jr. Clinical review 167: procalcitonin and the calcitonin gene family of peptides in inflammation, infection, and sepsis: a journey from calcitonin back to its precursors. J Clin Endocrinol Metab 2004;89:1512-25.

2. Buhaescu I, Yood RA, Izzedine H. Serum procalcitonin in systemic autoimmune diseases - where are we now? Semin Arthritis Rheum 2010;40:176-83.

3. Simon L, Gauvin F, Amre DK, Saint-Louis P, Lacroix J. Serum procalcitonin and $\mathrm{C}$-reactive protein levels as markers of bacterial infection: a systematic review and meta-analysis. Clin Infect Dis 2004;39:206-17.

4. Wu JY, Lee SH, Shen CJ, Hsieh YC, Yo PH, Cheng HY, et al. Use of serum procalcitonin to detect bacterial infection in patients with autoimmune diseases: a systematic review and meta-analysis. Arthritis Rheum 2012;64:3034-42.

5. Tombetti E, Manfredi A, Sabbadini MG, Baldissera E. Management options for Takayasu arteritis. Expert Opin Orphan Drugs 2013;1:685-93.

6. Vanoli M, Daina E, Salvarani C, Sabbadini MG, Rossi C, Bacchiani G, et al. Takayasu's arteritis: a study of 104 Italian patients. Arthritis Rheum 2005;53:100-7.

7. Redl H, Schiesser A, Togel E, Assicot M, Bohuon C. Possible role of TNF on procalcitonin release in a baboon model of sepsis. Shock 2001;16:25-7.

J Rheumatol 2014;41:7; doi:10.3899/jrheum.131340 